\title{
Macular degeneration and occupational risk factors: a systematic review
}

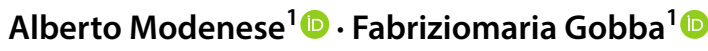

Received: 27 September 2017 / Accepted: 4 September 2018 / Published online: 6 September 2018

(c) The Author(s) 2018

\begin{abstract}
Purpose Macular degeneration is a multi-factorial disease, leading cause of blindness for people over 50 years old in developed countries. To date, the knowledge on possible occupational factors involved in the development of the disease is scant. Method We performed a systematic scientific literature search on the association between macular degeneration and occupational risk factors searching the MedLine and Scopus databases.

Results We examined 158 articles and, according to the inclusion criteria, 13 peer-reviewed studies evaluating occupational risk factors for macular degeneration or reporting the frequency of the disease in specific groups of workers were included in the review. Ten on thirteen articles evaluated the presence of macular degeneration in workers exposed to solar radiation. Only one study found that non-specific history of occupational chemical exposure was associated with the disease. Two studies showed an association between macular degeneration and the general category of "blue-collar" workers, but they did not identify the specific risk factors involved.

Conclusions To date few studies have examined occupational risk factors for macular degeneration. Nevertheless, available data indicate that long-term occupational solar radiation exposure, in particular for its blue-light component, is associated with macular degeneration in outdoor workers.
\end{abstract}

Keywords Macular degeneration · Occupational exposure $\cdot$ Solar radiation $\cdot$ Blue light $\cdot$ Ultraviolet radiation $\cdot$ Chemical exposure

\section{Introduction}

Macular degeneration (MD) is a chronic eye disease affecting the macula: the progressive loss of vision typical of the $\mathrm{MD}$, mainly in the centrum of the visual field, has a quite slow evolution and it can take years after the first diagnosis to induce an appreciable visual impairment (Christoforidis et al. 2011; Evans 2001; Shah et al. 2007). MD is currently the leading cause of blindness for people over 50 years old in developed countries (Taylor et al. 2001). Its prevalence in Europe is 3.3\% (Augood et al. 2006), and it is similar also

Electronic supplementary material The online version of this article (https://doi.org/10.1007/s00420-018-1355-y) contains supplementary material, which is available to authorized users.

Alberto Modenese

alberto.modenese@unimore.it

1 Department of Biomedical, Metabolic and Neural Sciences, University of Modena and Reggio Emilia, Via G. Campi 287, 41125 Modena, Italy in the US, where about 10 million of people are affected (Tomany et al. 2004a, b).

There are two major forms of MD, with different prognosis and therapy: the atrophic or dry-type MD, representing approximately the $85-90 \%$ of the total number of cases, and the neovascular or wet-type MD. The initial alteration of the fundus is often represented by the so-called drusen, or colloids bodies, that are degenerative formations of yellowish color and round shape mostly found at the posterior pole (Hughes et al. 2007; Virgili et al. 2015). Considering the mechanisms inducing the chronic retinal damage, an alteration of the metabolic sustainment of the photoreceptors cells (rods and cones) and of the retinal pigment epithelium (RPE) is supposed, depending on inflammation processes and vascular modifications (Gehrs et al. 2006; Nowak 2006).

MD is a multi-factorial disease: among the several risk factors involved in its etiology the most important is age (Hyman et al. 2002; Klein et al. 2004). Other recognized are smoke (Clemons et al. 2005; Fujihara et al. 2008), diabetes (Kearney et al. 2014), alcohol abuse (Baird et al. 
2014; Chong et al. 2018) and inheritance (Tuo et al. 2004; Yoshimura 2010), while a possible association with female gender (Cho et al. 2014) and other factors such as high C reactive protein levels, low antioxidant vitamins intake, dyslipidemia, fair iris color, previous cataract surgery (Chakravarthy et al. 2010; Ehmann et al. 2017; Gopinath et al. 2015; Kikuchi et al. 2007; Shaw et al. 2016) are supposed. Also an exposure to some chemicals, as lead and iron, was found to be associated with MD (Biesemeier et al. 2015; Hwang et al. 2015; Ugarte et al. 2013). Another MD risk factor is long-term exposure to optical radiation, in particular of the bands in the range of $400-550 \mathrm{~nm}$ of wavelength (near ultraviolet-UV-A-and visible "blue-light"), able to induce, in laboratories and animal models, a photochemical damage of the retina due to the formation of oxygen free radicals (OFR) (Sui et al. 2013; Wang et al. 2003). Eye exposure to optical radiation is mainly related to solar radiation and, consequently, outdoor workers (OWs) may be at risk, especially if they work on surfaces able to reflect optical radiation, as water, white sand, snow or shiny metals, as the eye is anatomically quite well protected from the solar rays coming from the sky (ICNIRP 2010; Modenese et al. 2018). Also artificial sources may induce relevant exposures of the eye to optical radiation, as in example indicator lamps and traffic signals, lamps used for the stage lighting and for projections, insect traps, LASERS, welding lights, etc (ICNIRP 2010; Modenese et al. 2016a; Thürauf 1979), but according to the current knowledge the main problems are related to acute eye exposures as a consequence of occupational eye injuries caused by optical radiations, that are quite rare events (Gobba et al. 2017; Kuckelkorn et al. 1995).

Considering these premises, among the various MD risk factors at least optical radiation and chemical exposure may be related to work, but to date the knowledge on specific occupational risk factors and on particular categories of workers at increased risk for MD is scant. It has to be also noted that, currently, the aging of the workforce is a growing problem worldwide (Poscia et al. 2016), and in the next years an increasing number of workers being diagnosed with MD is expected.

For these reasons our aim is to systematically review the recent development of research on the possible work-related risk of MD, studying if particular groups of workers have been found at risk for developing this disease and identifying the specific occupational risk factors detected in the studies and the methods applied to evaluate the exposure.

\section{Materials and methods}

An electronic search in accordance with Preferred Reporting Items for Systematic Reviews and MetaAnalyses (PRISMA) (Liberati et al. 2009) was performed in the Medline (through
PubMed) and Scopus databases. Broad limiters were set to include scientific literature covering a period of 50 years, from 1st March 1967 to 1st March 2017. The systematic review was limited to original research articles with an available English abstract published in peer-reviewed journals. Reviews, case reports, comments or letters were not considered. The following search string, modified by previous publications (Mattioli et al. 2010; Modenese et al. 2017), was built: "macular degeneration" AND (worker* OR job* OR occupation*).

Eligible were studies in which an assessment of the job history of patients with a MD diagnosis has been performed, and also studies in which workers have been investigated for the detection of the retinal disease. For the diagnosis of MD we considered clinical diagnosis made by an ophthalmologist and also studies evaluating surgical cases. We did not considered studies in which the subjects self-reported symptoms related to MD without a proved medical diagnosis or in which the cases were not humans.

Considering occupation, we included studies in which the specific occupation of the subjects was evaluated, and also studies considering a generic work categorization, such as "outdoor/indoor worker" or "white collar/blue collar worker".

Data extraction was performed by one reviewer and checked by another. The extraction was performed by reading all of the available abstracts of the studies returned from the input string in the two databases. Following this, full papers were retrieved for all of the works that met the inclusion criteria. The reference listings of the selected papers were also checked to find other significant research articles.

To assess the quality of the studies, each author independently rated the papers according to a modified version of the Newcastle-Ottawa Scale (Poole et al. 2017). This method results in a score between 0 and 10 , that can be assigned to the papers according to the following three domains:

- Selection bias domain: maximum 5 points; Items: (1) Is the sample representative of the population? (2) Was more than one site studied? (3) Was a power calculation undertaken? (4) Did the authors use standardized measurement tools to assess exposures? (5) Did the authors use standardized measurement tools to assess outcomes?

- Comparability domain: maximum 3 points; Items: (1) Were confounding factors assessed? (several considered: two points, some considered: one point, none: zero) (2) Did the study employ an appropriate control group?

- Outcome domain: maximum 2 points; Items: (1) Were statistical tests appropriate? (2) Were conclusions justified?

It was necessarily to adapt the method to our Systematic Review: as we did not have information on power calculation 
for none of the papers collected, but we could not exclude that this procedure was performed in some of the retrieved studies, we decided not to consider this aspect in the Selection Bias domain and accordingly the maximum total score in our analysis is 9 .

In case of disagreement in the evaluation, the two authors reconciled the differences in judgements through discussion.

\section{Results}

\section{Study selection}

The literature search resulted in 124 items from Medline and 128 items from Scopus. After the elimination of duplicates 158 articles have been selected. The two authors independently examined the abstracts and agreed on the studies to be included in the review according to criteria described in the "Methods" section 149 papers retrieved were excluded for the following reasons: 67 because they did not investigate, nor estimate, an occupational exposure to a specific risk factor in relation to the outcome of interest (i.e., macular degeneration, MD), 37 and 19 as they were review/letters/ comments and because not written in English language, respectively, 19 because did not specifically investigate the outcome of interest (i.e., macular degeneration), 6 because were on animals and, finally 1 as was a case report. 9 on 158 studies were finally selected, and four more studies were identified from a hand search of the references; as a consequence, in this review a total of 13 studies is included (Fig. 1).

\section{Synthesis of the results}

Table 1 summarizes the main characteristics and findings of the 13 studies reviewed, including the occupational risk factors considered and their evaluation methods, and reporting the odds ratio, crude or adjusted for specific confounders. Furthermore, the different types of MD studied, with

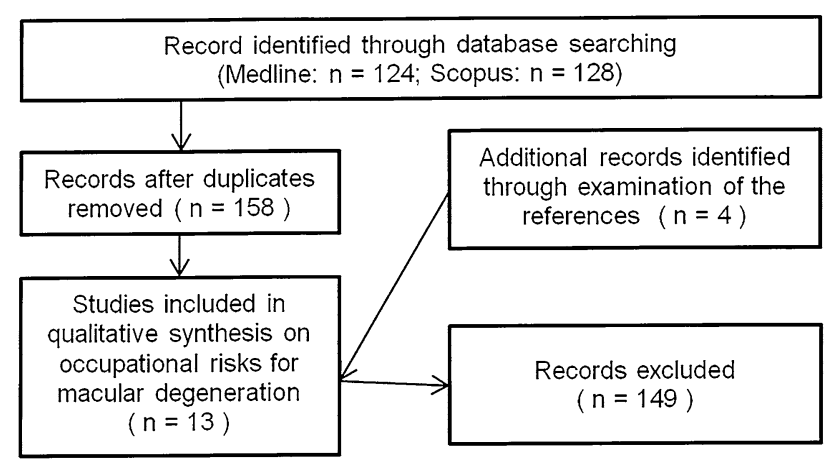

Fig. 1 Selection process of the reviewed studies grading and diagnosing methods applied, when reported by authors, are shown in Table 1, as well as other relevant results of the studies on associations between MD and other factors. Finally, in Table 1 we report also the scoring (range $0-9$ ) attributed to the papers retrieved, based on the quality assessment performed according to an adapted version of the Newcastle-Ottawa Scale (see "Materials and methods" section); the details of the evaluation, including the domains considered, are presented in Table 2.

Of the 13 articles included in our Systematic Review, 10 evaluated the presence of MD in OW exposed to solar radiation (SR). 4 Croatian studies assessed the frequency of MD simply considering occupational SR exposure classifying workers as OW or indoor workers (IW). Njiric et al. (2007) performed a retrospective study including all the patients visiting the Eye Polyclinic of Rijeka in Croatia during the years 1995, 2000 and 2005, for a total of 6617 subjects. The incidence of MD resulted $0.75 \%$ in $1995,0.93 \%$ in 2000 and $1.07 \%$ in 2005 . The patients were divided in two groups according to the outdoor or indoor occupation: the $1.9 \%$ of the $\mathrm{OW}$ were diagnosed with MD during the 3 years of observation, VS only the $0.8 \%$ of the IWs $(p<0.001)$. Vojnikovic et al. (2007) found a higher MD frequency in farmers and fishermen of the Rab island (Adriatic Sea, $44^{\circ} 40^{\prime} \mathrm{N}$ ), within a sample of 1371 subjects aged $45-65$ years, followed for a biennium. MD was diagnosed in the $18 \%$ of the OW, while only in the $2.5 \%$ of the IWs. PlestinaBorjan et al. (2007) conducted a study in 632 subjects over 50 years, of which 420 were mainly fishermen, seamen and farmers from a Croatian island, while the others were from Zagreb city. MD prevalence was higher in OW from the island than in subject from Zagreb, 34.3 vs $16 \%$, respectively, and it was significantly associated with mean daily SR exposure $\left(X^{2}=216.4 ; p=0.000\right)$. Caljkusic-Mance et al. (2010) evaluated the occupation history in a sample of 60 patients, median age was 70.2 (range 52-86), diagnosed with dry or wet MD during years 2008 and 2009 in an ophthalmologic clinic in Croatia. 42 cases were OW (70\%) and 18 patients were IW $(30 \%)(p<0.0001)$.

Another hospital-based 9 months prospective study from Nepal (Thapa et al. 2011) considered the occupation of a sample of patients representing all the consecutive cases of MD diagnosed from September 2008 to May 2009 at the local institute of ophthalmology. A total of 141 patients were recruited (mean age 69.5 years) and, considering work activity, the $42.5 \%$ of the sample were agriculture workers $(p=0.077)$ with occupational SR exposure.

In the previous studies workers were simply classified as outdoor or indoor workers, while in the following studies a detailed assessment of SR exposure has been performed. In a recent multi-centric European study conducted by Shick et al. (2016), SR exposure and job history were investigated with a detailed questionnaire. The 
Table 1 Main characteristics and results of the studies included in the systematic review on macular degeneration and exposure to occupational risk factors

\begin{tabular}{|c|c|c|c|c|}
\hline First author, year & Place & $\begin{array}{l}\text { Subjects group/sample size } \\
(n)\end{array}$ & $\begin{array}{l}\text { Occupational risk factor associated (if identified), MD subtype } \\
\text { and severity (if provided) and MD frequency (if available), } \\
\text { other relevant results of the study }\end{array}$ & $\begin{array}{l}\text { Quality } \\
\text { score } \\
(0-9)\end{array}$ \\
\hline
\end{tabular}

Retrospective/prospective

Thapa, 2011

Nepal

PtA/141

Njiric, 2007

Croatia

PtA/6617

Vojnikovic 2007

Croatia

Wo/1371

Klein, 2001

US

$\mathrm{GP}(\mathrm{A}) / 3672$

Bressler, 1995

US

Wo/483

Cross sectional/case-control

Saadat, 2012

Iran

$\mathrm{PtA} / 223$

Plestina-Borjan, 2007 Croatia
SR-OW (based on job title)

Sample composition $=42.6 \%$ farmers (most frequent job)

Dry vs wet $\mathrm{MD}=62.4 \%$ vs $37.6 \%$; in farmers 55 vs $45 \%$ $(p=0.077)$

SR-OW (based on job title)

3-years MD (any grade) incidence $=1.9 \% \mathrm{OW}$ (total number $=463 ; 7 \%$ of the sample $)$ vs $0.8 \%$ IW $(p<0.001)$

SR-OW (based on job title)

2 -year MD (any grade) incidence $=18 \% \mathrm{OW}$ (farmers, fishermen $=95 \%$ of the sample) vs $2.5 \%$ IW

2-year incidence of central vision loss: $21 \%$ OW vs $4 \%$ IW

2-year incidence of glaucoma (suspected): $28 \%$ OW vs $0 \%$ IW

5 -years incidence of early stage $\mathrm{MD}=17 \%$ for waiters; $13 \%$ for cooks; $21 \%$ for bartenders; $13 \%$ for cleaning services personnel

History of service occupation (based on job title)

Waiters, cooks, bartenders, cleaning personnel: OR $*=1.8$

(1.01-3.3), compared to white collar workers

Blue collar vs white collar workers: OR $*=1.2(0.9-1.6)$

Farmers vs white collar: OR $*=0.5(0.2-1.15)$

Other results: $13-15$ years of education $\mathrm{vs}<12$ : $\mathrm{OR}^{*}=0.4$ (0.25-0.7)

*Adjusted for age and sex

SR-OW (based on job title): 5-years incidence in Maritime workers $=$ Grade 3 MD*: age adjusted 9\% (30-39 ys: 7\%; 40-49 ys: 4\%; 50-59 ys: 7\%; 60-69 ys: $14 \%$; >70 ys: $26 \%)$

Grade $4 \mathrm{MD}$ : neovascular disease developed in $1 \mathrm{OW}(0.2 \%)$, geographic atrophy in none

* Classified as eyes with one or more of the following: large or confluent drusen and/or focal hyperpigmentation and/or nongeographic atrophy of the retinal pigmented epithelium

Cumulative sunlight exposure of the maritime workers who developed Grade 3 and $4 \mathrm{MD}=0.84 \pm 0.63$ Maryland sun years (standard annual SR exposure in Maryland, US; based on an integrated method combining subjective data collected with a questionnaire, environmental SR irradiance data with meteorological database and modelisation to determine personal ocular exposure)

SR-OW (based on job title): polymorphism of gene XRCC7 in OW with exudative MD: OR 3.1 (CI 95\%, 1.04-9.4; $p=0.042)$, adjusted for age, compares with IW

$\mathrm{OW}=77$ subjects $(34.5 \%$ of the sample); $\mathrm{OW}$ with $\mathrm{MD}=51$ (23\%)

SR-OW (based on job title): 113 maritime workers and farmers with SR exposure $>8 \mathrm{~h}$ /day had MD, $X^{2} 186.22$, $p<0.001$

Prevalence of different grades* of MD in 420 OWs. Grade 4: 4.2\%; grade 3: $4.2 \%$; grade 2 : $14.0 \%$; grade 1: $11 \%$

* Grading of MD: same classification as Taylor (1990) (see below) 
Table 1 (continued)

\begin{tabular}{|c|c|c|c|c|}
\hline First author, year & Place & $\begin{array}{l}\text { Subjects group/sample size } \\
(n)\end{array}$ & $\begin{array}{l}\text { Occupational risk factor associated (if identified), MD subtype } \\
\text { and severity (if provided) and MD frequency (if available), } \\
\text { other relevant results of the study }\end{array}$ & $\begin{array}{l}\text { Quality } \\
\text { score } \\
(0-9)\end{array}$ \\
\hline
\end{tabular}

Hyman, 1983 US PtA/465

Occupational chemical exposure (based on questionnaire investigation), history of: $\mathrm{OR}^{*}=4.2(1.1-15.2)$. Considering only males: $\mathrm{OR}^{*}=3.8(1.0-14.5)$

Other associated factors: inheritance $\mathrm{OR}^{*}=2.9(1.5-5.5)$

Cigarette smoking in males: $\mathrm{OR}^{*}=2.6(1.15-5.75)$

History of cardiovascular diseases: $\mathrm{OR}^{*}=1.9(1.03-3.34)$

*Adjusted for age and sex

Cross sectional

Schick, 2016

Europe

$\operatorname{PtA} / 3701$

Park, 2014

South Korea

Caljkusic-Mance, 2010 Croatia

$\operatorname{PtA} / 60$

Fletcher, 2008

Europe
Prevalence $=20.3 \%$ early MD*; $31.9 \%$ late MD*

SR-OW (based on job title and subjective investigation of SR exposure history with a questionnaire): $\mathrm{OR}^{* *}$ (compared with IW) $=2.6(1.9-3.5)$ for late MD*; n.a. for early MD*

Past SR exposure $>8 \mathrm{~h} /$ day: $\mathrm{OR}^{* *}$ (compared with "avoiding the sun") $=6.3(1.4-27.5)$ for early $\mathrm{MD} ;=2.6(1.3-5.2)$ for late MD

*Early MD = presence of at least 10 small drusen and pigmentary changes

Late MD = either MD with geographic atrophy and/or choroidal neovascularization in at least one eye

**Adjusted for age, gender, and smoking behavior

GP(A)/14352 Age weighted prevalence: $6.6 \%$ for all forms; $6 \%$ early MD*; 8 $0.6 \%$ all late $\mathrm{MD} *$ forms; $0.5 \%$ wet late $\mathrm{MD} * ; 0.1 \%$ geographic atrophy*

Blue collar workers vs white collar OR** $=2.0(1.5-2.6)$

Not occupied vs white collar OR** $=1.6(1.2-2.1)$

Other risk factors: low education vs high $\mathrm{OR}^{* *}=1.5(1.2-1.9)$

Anemia: $\mathrm{OR}^{* *}=1.4(1.0-1.9)$; HBsAg carrier: $\mathrm{OR}^{* *}=1.9$ $(1.3-2.7)$

*Early MD if presence of soft indistinct/reticular drusen, or presence of hard or soft distinct drusen with pigmentary abnormalities. Late MD: wet MD or geographic atrophy (GA). Wet = retinal pigment epithelial detachment or serous detachment of the sensory retina, subretinal or sub-RPE hemorrhages, and subretinal fibrous scars. GA = circular discrete area of retinal depigmentation with visible choroidal vessels

**Adjusted for age, gender and smoking status

Among the MD cases, $75 \%$ dry (atrophic) MD, 25\% wet (neovascular) MD

SR-OW (based on job title): OW $(n=42)$ vs controls: 70 vs $30 \%\left(X^{2}=17.6, p<0.0001\right)$

GP(A)/4753 Prevalence of MD according to severity* in subjects $>65$ years: grade $4 \mathrm{MD}$ (neovascular) $=2.3 \%$; grade 4 (geographic atrophy $)=1 \%$; early MD (grade $1+2+3)=45.9 \%$; grade $1=36.5 \%$; grade $2=10.1 \%$; grade $3=2.5 \%$

SR-OW (based on an integrated method combining subjective data collected with a questionnaire, environmental SR irradiance data with meteorological database and modelisation to determine personal ocular exposure, considering also the blue-light component): subjects with lowest dietary intake of antioxidants and high blue light exposure in central hours of the day

$\mathrm{OR}^{* *}=3.72(1.56-8.88)$ for neovascular MD vs atrophic

$\mathrm{OR}^{* *}=1.95(1.06-3.58)$ for grade $3 \mathrm{MD}$ vs grade 0

* Grading of MD: same classification as Taylor (1990) (see below)

**Adjusted for age, sex, smoking, diabetes, cardiovascular disease, education, aspirin use, retinol, cholesterol 
Table 1 (continued)

\begin{tabular}{|c|c|c|c|c|}
\hline First author, year & Place & $\begin{array}{l}\text { Subjects group/sample size } \\
(n)\end{array}$ & $\begin{array}{l}\text { Occupational risk factor associated (if identified), MD subtype } \\
\text { and severity (if provided) and MD frequency (if available), } \\
\text { other relevant results of the study }\end{array}$ & $\begin{array}{l}\text { Quality } \\
\text { score } \\
(0-9)\end{array}$ \\
\hline Taylor, 1990 & US & Wo/782 & $\begin{array}{l}\text { MD prevalence in maritime workers according to sever- } \\
\text { ity }=27.6 \% \text { grade } 1 ; 18.9 \% \text { grade } 2 ; 12.0 \% \text { grade } 3 ; 1.2 \% \\
\text { grade } \\
\text { SR-OW (based on an integrated method combining subjective } \\
\text { data collected with a questionnaire, environmental SR irradi- } \\
\text { ance data with meteorological database and modelisation } \\
\text { to determine personal ocular exposure, considering also the } \\
\text { blue-light component): ocular blue light exposure (past } 20 \\
\text { years, OWs }>50 \text { years old) }=\text { OR**: } 1.35(1.0-1.8 \text { ) for grade } \\
4 \text { MD, n. s. considering other MD grades, n. s. considering } \\
\text { ocular UV exposure } \\
\text { *Classification grade } 1=<20 \text { small drusen; grade } 2>20 \text { or } \\
\text { more small drusen in central; grade } 3 \text { large or confluent } \\
\text { drusen, focal hyperpigmentation; grade } 4 \text { exudative disease, } \\
\text { geographic atrophy } \\
\text { **Logistic regression analysis: increase in exposure of } 0.1 \\
\text { MSY (standard annual SR exposure in Maryland, US) }\end{array}$ & 8 \\
\hline
\end{tabular}

$G P(A)$ general population (adults), $I W$ indoor workers, $M D$ macular degeneration, $O R$ odd ratio (confidence interval $95 \%$ ), $O W$ outdoor workers, $P t A$ patients (adults), n.a. no association, $n$. s. not significant, $S R$ solar radiation exposure, Wo workers

results showed a prevalence of MD in general population of $20.3 \%$ for early MD and $31.9 \%$ for late MD. MD was not found to be associated with current SR exposure, but both, early and late MD, proved association with a history of past sunlight exposure major than $8 \mathrm{~h}$ outdoor per day, typical of outdoor work, with an OR for early MD of 5.54 (95\% CI 1.25-24.58), and of 2.77 (95\% CI 1.25-6.16, $p=0.01$ ) for late MD. Furthermore, OW was more likely to have late MD with an OR of 2.57 (1.89-3.48), after adjustment for age, gender, and smoking behavior, while no association with early MD was found. In another multicentric European study (Fletcher et al. 2008), a more detailed method for SR exposure evaluation was adopted. In 4753 participants, aged 65 years or older, fundus photography was collected and in 101 individuals neovascular MD was diagnosed, in 2182 early MD was found and 2117 subjects were classified as controls. All subjects were interviewed for adult lifetime sunlight exposure, and gave blood for antioxidant analysis. SR exposure was estimated by combining meteorological and questionnaire data. The questionnaire evaluated the history of sunlight exposure in various occupational periods of life, investigating for each period the number of hours spent outdoor between 9 am and $5 \mathrm{pm}$, and specifically between 11 am and $3 \mathrm{pm}$, and the adoption of protective equipment such as hat and sunglasses. For all residences of 1 year or longer, ambient UVB and UVA were estimated from environmental databases, and blue light was estimated using a radiation model that estimates spectral radiation as a function of time of day, day of the year, and latitude; exposure was adjusted for coefficients for cloud cover, surfaces, and protections. The Authors did not report a direct association between SR exposure in outdoor workers and MD, but observed a significant association in subjects with the lowest dietary intake of antioxidants and high blue light exposure in midday hours with an OR of 1.95 (1.06-3.58) for grade $3 \mathrm{MD}$ vs grade 0 .

History of cumulative exposure to the blue light component of SR exposure was found to be associated with severe MS (grade 4) also in the "watermen study" performed in Maryland, US, by Taylor et al. (1990) in late 80 s. 838 maritime workers underwent an ophthalmologic examination and grade $4 \mathrm{MD}$ showed a prevalence of $1.2 \%$. Cumulative sunlight exposure was evaluated with a mixed model, including laboratory measurements of eye exposure, environmental data available through meteorological databases and a questionnaire administration. This method estimated the exposure for the different optical radiation bands of SR, UVA, UVB and blue light and the data was reported as a fraction of a standard "Maryland Sun-Year", representing the mean SR exposure in 1 year typical of this US country: grade 4 MD was significantly more frequent in watermen with an increasing of 0.1 "Maryland Sun Years" of blue light exposure for a period of 20 years, OR $1.35(1.0-1.81)$, while no significant association was found for the UV components. This study represented the baseline evaluation for the longitudinal study of Bressler et al. (1995), aimed to evaluate the 5-year MD incidence in 483 Maritime workers who underwent a follow-up examination. The MD incidence increased with OWs age: $7 \%$ in the age group $50-59$ years (ys), $14 \%$ in $60-69$ ys and $26 \%$ in $>70$ ys. Also in this study SR exposure was evaluated with the same semi-quantitative 


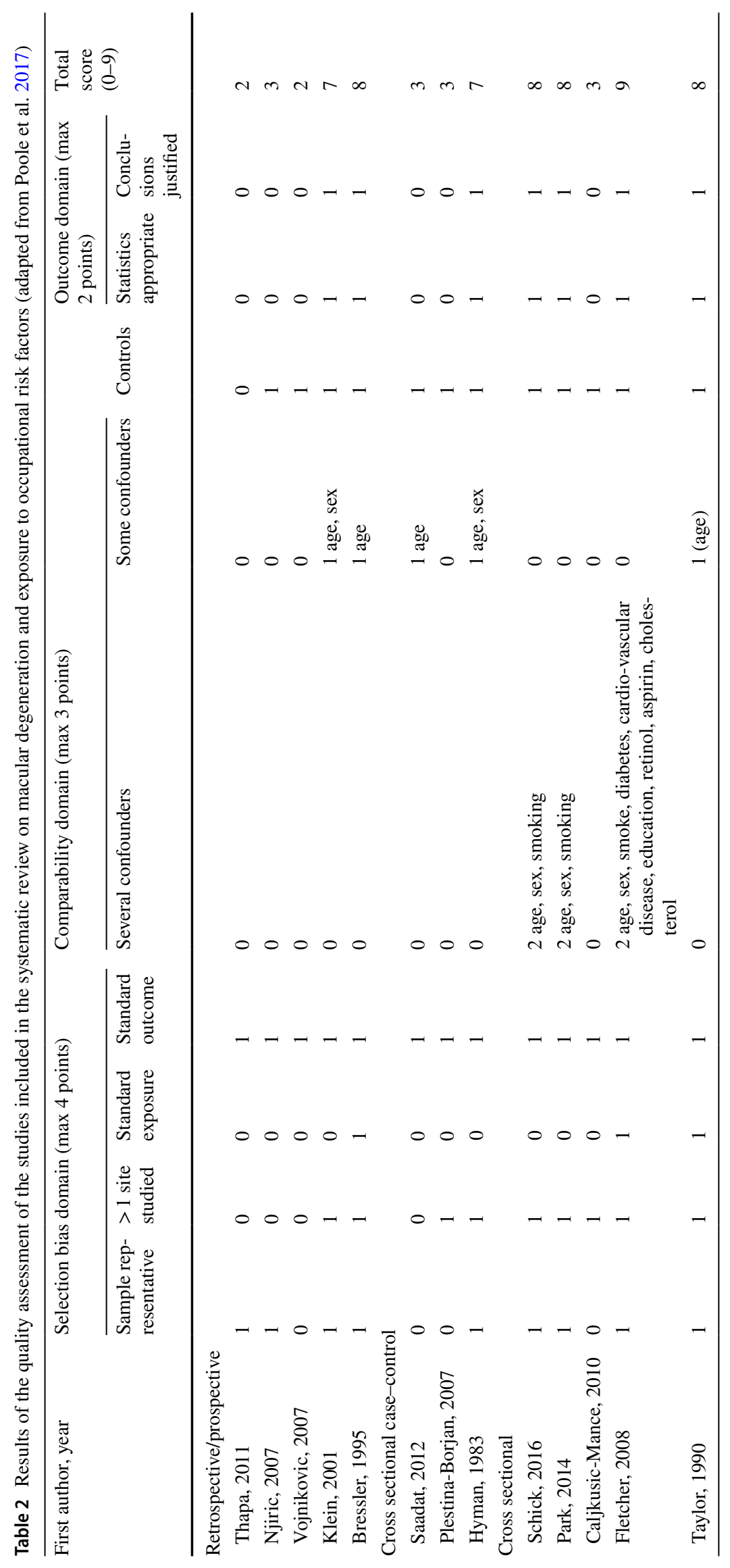


method used by Taylor et al., and cumulative SR exposure resulted $0.84 \pm 0.63$ "Maryland sun years" in the group of maritime workers followed.

Finally, a different type of study investigating a sample of 111 patients with exudative MD classified as outdoor or indoor workers according to their job titles was performed in Iran by Saadat et al. (2012). The aim of the study was to investigate the presence of polymorphism of the Gene XRCC7, located on human chromosome 8q12, where contiguous markers possibly associated with MD have previously been identified. This gene encodes the catalytic subunit of a nuclear DNA-dependent serine/threonine protein kinase, contributing in the recognition and repair of DNA double-strand breaks, found to be associated with cancer by other Authors. Saadat et al. found that the presence of gene XRCC7 polymorphism was significantly highly expressed in OWs than in indoor workers with MD, OR 3.1 (1.04-9.39), $p=0.042$.

Moving now to possible other occupational MD risk factors, two studies investigated the occupation activity in large samples of population, but without hypothesizing a specific factor involved. Klein et al. (2001) performed a longitudinal examination of the cohort of the "Beaver Dam Eye Study", Wisconsin-US-, composed by 3681 adults (range 43-86 years of age at baseline). Status and type of employment were investigated with a questionnaire and fundus photography was collected to diagnose MD. Blue collar workers compared with white collars were more luckily to have early MD $(p<0.05)$, and in particular a higher 5-year MD incidence was observed in waiters (17\%), cooks (13\%) and bartenders (21\%), and in personnel involved in cleaning services (13\%) versus other working categories, including farmers (OR 1.83, CI 95\% 1.01-3.32). Also in the SouthKorean study of Park et al. (2014) the prevalence of MD was found to be higher in blue collar workers than in white collars, with a significant OR of 1.82 (95\% CI 1.37-2.42, $p<0.001$ ). This study was conducted from 2008 to 2011 in 14,352 participants over 40 years of age examined with fundus photographs, diagnosing MD in the $6.6 \%$ of the sample, of which $6 \%$ early MD and $0.6 \%$ late MD. Demographic and socioeconomic factors were investigated with a questionnaire; no association with sun exposure evaluated independently of the job, as major than $5 \mathrm{~h}$ per day pent in the sun, was found.

Finally the case-control study performed in Baltimore, U.S., by Hyman et al. (1983) considered 162 cases of MD and 175 controls matched by age and sex. Study participants were examined with fundus photographs and interviewed for past medical, residential, occupational, smoking and family histories, as well as social and demographic factors. Diagnoses were validated by means of fundus photographs. A statistically significant association was shown between MD and non-specific occupational chemical exposure investigated with the question "Did you ever work around chemicals which caused your eyes to burn, on a regular basis?", OR 4.2 (95\% CI 1.1-15.2).

\section{Discussion}

\section{Main findings of the studies reviewed}

In most studies included in this systematic review (10/13) the risk related to occupational solar radiation exposure was evaluated; all the ten studies found a positive association between SR exposure and MD. These results are in agreement with scientific literature, showing an OR of 2.09 (95\% CI 1.19-3.65) for SR exposure and early MD (Cruickshanks et al. 2001), and a relative risk of 2.20 (95\% CI 1.02-4.73) (Tomany et al. 2005) in general population; these studies have been also included in a recent systematic review and meta-analysis (Sui et al. 2013) of 14 studies, 12 of which showed an increased risk of MD for high levels of SR exposure, and in 6 cases the associations were statistically significant. In six studies the occupational SR exposure was evaluated simply classifying workers as outdoor or indoor, while in four studies the exposure was evaluated with a more detailed method, considering subjective and objective data: two of these studies estimated, among the SR components, the contribution of different optical bands and found a specific association between MD and cumulative blue light exposure, not for the UV components. It has to be considered that, among the ultraviolet component, only a part of UV-A from 380 to 400 nanometers (nm) of wavelength can reach the retina with a possible chronic photochemical damage, especially in younger ages, while UV bands below $380 \mathrm{~nm}$ are absorbed in the anterior eye (Sliney 2002). The other optical bands of SR able to interact with macular cells with photochemical mechanisms are the visible "bluelight" bands between 400 and $550 \mathrm{~nm}$ of wavelength. The remaining part of the visible spectrum, as well as the infrared bands, reach the retina, but the interactions mechanisms are based on the possible thermal effects, mainly relevant in inducing acute disorders (ICNIRP 2004; Sliney 2002; Sliney et al. 2005).

Quite surprisingly, we found no studies evaluating the presence of MD in groups of workers exposed to artificial optical radiation, such as welders (Maier et al. 2005; Tenkate 2017), health personnel (Price et al. 2016) and others. It has to be noted that, as in example, in Europe, according to the Directive 2006/25/EC, for artificial optical radiation exposure specific occupational limits for blue light and UV have to be respected to protect the eye (ICNIRP 2004; Sliney 2002; Sliney et al. 2005), as well as for the skin (ICNIRP 2004; Modenese et al. 2016b; Ulrich et al. 2016). 
The other work-related risk for MD found in this review is a non-specific history of chemical exposure at work, found to be associated with MD in a 1983 U.S. study (Hyman et al. 1983). This result may be supported by some more recent studies suggesting that chemicals like lead and iron can accumulate in the macula inducing a chronic damage, while the depletion of fundamental chemicals like zinc may play a role in the failure of the protective antioxidant mechanisms (Biesemeier et al. 2015; Hwang et al. 2015; Ugarte et al. 2013).

Other two studies reviewed did not evaluate specific occupational risk factors, finding an association between MD and the general category of "blue-collar" workers: SR exposure may be involved, but also chemical exposure and possibly other factors; in the longitudinal U.S. study by Klein et al. the specific "blue collar" categories at higher risk were that of waiters, cooks, bartenders and cleaning personnel, and it is not clear what occupational risk factor can be involved, even if, at least for cleaning personnel, chemical exposure may be considered.

\section{Limitations of the review}

The quality of the analysis performed in the studies reviewed is rather inhomogeneous, and some weak aspects can be observed. On the other hand, especially considering the scarce number of studies published, to analyze all the literature of interest, we decided not to exclude any pertinent study on the topic of "occupational risk factors for macular degeneration". Another problem is that the study designs applied by researchers are quite different and scarcely comparable, precluding any possibility of a meta-analysis. Based on our quality assessment, 6 on 13 studies showed a rather poor quality, presenting problems in particular in the exposure assessment phase and in the selection of the sample. These six studies (Caljkusic-Mance et al. 2010; Njiric et al. 2007; Plestina-Borjan et al. 2007; Saadat et al. 2012; Thapa et al. 2011; Vojnikovic et al. 2007) considered MD and SR exposure of outdoor workers. The main issue in all these studies is the exposure evaluation that was only based on job title; moreover, in some studies is not clear the criteria for enrollment and for assignation of the subjects to the OW or IW groups. Also the statistical analysis performed in these six studies is not adequate to fully support their conclusions. On the other hand, four very well designed studies, including a large number of subjects and a solid methodology for the assessment of both outcome and exposure, support an association between MD and occupational sunlight exposure, especially considering the cumulative ocular blue-light exposure (Bressler et al. 1995; Fletcher et al. 2008; Schick et al. 2016; Taylor et al. 1990). Other three well designed studies, with representative samples, good outcome definition and adequate statistics (Hyman et al. 1983; Klein et al.
2001; Park et al. 2014) consider other possible occupational risk factors, but the exposure assessment is based on a subjective evaluation, not allowing any affordable inference regarding a possible association between the investigated occupational risk factors (e.g., chemical exposure) and MD. This topic certainly deserves further research with more adequate methods.

\section{Conclusions}

To date few studies have examined occupational risk factors associated with MD, as well as few studies evaluated the frequency of this disease in specific working groups. Nevertheless, available data support the hypothesis of an association between long-term occupational SR exposure, in particular for its blue-light component, and MD in outdoor workers. According to the high number of OWs worldwide (e.g., about 15 million only in Europe) and to the high prevalence of the disease in people aged 50 years or more, these results suggest the opportunity of specific organizational and individual protective measures to prevent this disease, possibly including a medical examinations of the workers' eyes. No studies on the relations between occupational exposures to artificial light and MD were found, while some studies suggest that occupational exposure to chemicals may represent a possible risk factor for MD. Overall, the scarce number of studies, and their inhomogeneous quality, supports the need of further research on the possible association between MD and occupational risk factors.

Open Access This article is distributed under the terms of the Creative Commons Attribution 4.0 International License (http://creativeco mmons.org/licenses/by/4.0/), which permits unrestricted use, distribution, and reproduction in any medium, provided you give appropriate credit to the original author(s) and the source, provide a link to the Creative Commons license, and indicate if changes were made.

\section{References}

Augood CA, Vingerling JR, de Jong PT, Chakravarthy U, Seland J, Soubrane G, Tomazzoli L, Topouzis F, Bentham G, Rahu M, Vioque J, Young IS, Fletcher AE (2006) Prevalence of age-related maculopathy in older Europeans: the European Eye Study (EUREYE). Arch Ophthalmol 124(4):529-535. https://doi.org/10.1001/ archopht.124.4.529

Baird PN, Chakrabarti S (2014) How genetic studies have advanced our understanding of age-related macular degeneration and their impact on patient care: a review. Clin Exp Ophthalmol 42(1):5364. https://doi.org/10.1111/ceo.12235

Biesemeier A, Yoeruek E, Eibl O, Schraermeyer U (2015) Iron accumulation in Bruch's membrane and melanosomes of donor eyes with age-related macular degeneration. Exp Eye Res 137:39-49. https://doi.org/10.1016/j.exer.2015.05.019 
Bressler NM, Munoz B, Maguire MG, Vitale SE, Schein OD, Taylor HR, West SK (1995) Five-year incidence and disappearance of drusen and retinal pigment epithelial abnormalities. Waterman study. Arch Ophthalmol 113(3):301-308. https://doi.org/10.1001/ archopht.1995.01100030055022

Caljkusić-Mance T, Kovacević D, Novak-Stroligo M, Alpeza-Dunato Z (2010) Distribution of age-related macular degeneration in Primorsko-Goranska County. Coll Antropol 34(Suppl.2):109-111

Chakravarthy U, Wong TY, Fletcher A, Piault E, Evans C, Zlateva G, Buggage R, Pleil A, Mitchell P (2010) Clinical risk factors for age-related macular degeneration: a systematic review and meta-analysis. BMC Ophthalmol 10:31. https://doi. org/10.1186/1471-2415-10-31

Cho BJ, Heo JW, Shin JP, Ahn J, Kim TW, Chung H (2014) Association between reproductive factors and age-related macular degeneration in postmenopausal women: the Korea National Health and Nutrition Examination Survey 2010-2012. PLoS One 9(7):e102816. https://doi.org/10.1371/journal.pone.0102816

Chong EW, Kreis AJ, Wong TY, Simpson JA, Guymer RH (2008) Alcohol consumption and the risk of age-related macular degeneration: a systematic review and meta-analysis. Am J Ophthalmol 145(4):707-715. https://doi.org/10.1016/j.ajo.2007.12.005

Christoforidis JB, Tecce N, Dell'Omo R, Mastropasqua R, Verolino M, Costagliola C (2011) Age related macular degeneration and visual disability. Curr Drug Targets 12(2):221-233. https://doi. org/10.2174/138945011794182755

Clemons TE, Milton RC, Klein R, Seddon JM, Ferris FL 3rd; AgeRelated Eye Disease Study Research Group (2005) Risk factors for the incidence of advanced age-related macular degeneration in the Age-Related Eye Disease Study Research (AREDS) AREDS report no. 19. Ophthalmology 112(4):533-539. https:// doi.org/10.1016/j.ophtha.2004.10.047

Cruickshanks KJ, Klein R, Klein BE, Nondahl DM (2001) Sunlight and the 5-year incidence of early age-related maculopathy: the beaver dam eye study. Arch Ophthalmol 119(2):246-250. https:// doi.org/10.1001/pubs.Ophthalmol

Ehmann DS, Ho AC (2017) Cataract surgery and age-related macular degeneration. Curr Opin Ophthalmol 28(1):58-62. https://doi. org/10.1097/ICU.0000000000000331

Evans JR (2001) Risk factors for age-related macular degeneration. Prog Retin Eye Res 20(2):227-253. https://doi.org/10.1016/S1350 -9462(00)00023-9

Fletcher AE, Bentham GC, Agnew M, Young IS, Augood C, Chakravarthy U, de Jong PT, Rahu M, Seland J, Soubrane G, Tomazzoli L, Topouzis F, Vingerling JR, Vioque J (2008) Sunlight exposure, antioxidants, and age-related macular degeneration. Arch Ophthalmol 126(10):1396-1403. https://doi.org/10.1001/ archopht.126.10.1396

Fujihara M, Nagai N, Sussan TE, Biswal S, Handa JT (2008) Chronic cigarette smoke causes oxidative damage and apoptosis to retinal pigmented epithelial cells in mice. PLoS One 3(9):e3119. https:// doi.org/10.1371/journal.pone.0003119

Gehrs KM, Anderson DH, Johnson LV, Hageman GS (2006) Agerelated macular degeneration-emerging pathogenetic and therapeutic concepts. Ann Med 38(7):450-471. https://doi. org/10.1080/07853890600946724

Gobba F, Dall'Olio E, Modenese A, De Maria M, Campi L, Cavallini GM (2017) Work-related eye injuries: a relevant health problem. Main epidemiological data from a highly-industrialized area of northern Italy. Int J Environ Res Public Health. https://doi. org/10.3390/ijerph14060604

Gopinath B, Flood VM, Kifley A, Liew G, Mitchell P (2015) Smoking, antioxidant supplementation and dietary intakes among older adults with age-related macular degeneration over 10 years. PLoS One 10(3):e0122548. https://doi.org/10.1371/journal.pone.01225 48
Hughes AE, Orr N, Patterson C, Esfandiary H, Hogg R, McConnell V, Silvestri G, Chakravarthy U (2007) Neovascular age-related macular degeneration risk based on CFH, LOC387715/HTRA1, and smoking. PLoS Med 4(12):e355. https://doi.org/10.1371/ journal.pmed.0040355

Hwang HS, Lee SB, Jee D (2015) Association between blood lead levels and age-related macular degeneration. PLoS One 10(8):e0134338. https://doi.org/10.1371/journal.pone.0134338

Hyman L, Neborsky R (2002) Risk factors for age-related macular degeneration: an update. Curr Opin Ophthalmol 13(3):171-175

Hyman LG, Lilienfeld AM, Ferris FL 3rd, Fine SL (1983) Senile macular degeneration: a case-control study. Am J Epidemiol 118(2):213-227. https://doi.org/10.1093/oxfordjournals.aje. a113629

International Commission on Non-Ionizing Radiation Protection (2004) Guidelines on limits of exposure to ultraviolet radiation of wavelengths between $180 \mathrm{~nm}$ and $400 \mathrm{~nm}$ (incoherent optical radiation). Health Phys 87(2):171-186. https://doi. org/10.1097/00004032-200408000-00006

International Commission on Non-Ionizing Radiation Protection (2010) ICNIRP statement-protection of workers against ultraviolet radiation. Health Phys 99(1):66-87. https://doi. org/10.1097/HP.0b013e3181d85908

Kearney FM, Fagan XJ, Al-Qureshi S (2014) Review of the role of refined dietary sugars (fructose and glucose) in the genesis of retinal disease. Clin Exp Ophthalmol 42(6):564-573. https:// doi.org/10.1111/ceo.12290

Kikuchi M, Nakamura M, Ishikawa K, Suzuki T, Nishihara H, Yamakoshi T, Nishio K, Taki K, Niwa T, Hamajima N, Terasaki H (2007) Elevated C-reactive protein levels in patients with polypoidal choroidal vasculopathy and patients with neovascular age-related macular degeneration. Ophthalmology 114(9):17221727. https://doi.org/10.1016/j.ophtha.2006.12.021

Klein R, Klein BE, Jensen SC, Moss SE (2001) The relation of socioeconomic factors to the incidence of early age-related maculopathy: the Beaver Dam eye study. Am J Ophthalmol 132(1):128131. https://doi.org/10.1016/S0002-9394(00)00931-4

Klein R, Peto T, Bird A, Vannewkirk MR (2004) The epidemiology of age-related macular degeneration. Am J Ophthalmol 137(3):486-495. https://doi.org/10.1016/j.ajo.2003.11.069

Kuckelkorn R, Kottek A, Schrage N, Reim M (1995) Poor prognosis of severe chemical and thermal eye burns: the need for adequate emergency care and primary prevention. Int Arch Occup Environ Health 67(4):281-284

Liberati A, Altman DG, Tetzlaff J, Mulrow C, Gotzsche PC, Ioannidis JP et al (2009) The PRISMA statement for reporting systematic reviews and meta-analyses of studies that evaluate health care interventions: explanation and elaboration. J Clin Epidemiol 62(10):e1-e34. https://doi.org/10.1016/j.jclin epi.2009.06.006

Maier R, Heilig P, Winker R, Neudorfer B, Hoeranter R, Ruediger H (2005) Welder's maculopathy? Int Arch Occup Environ Health 78(8):681-685. https://doi.org/10.1007/s00420-005-0013-3

Mattioli S, Zanardi F, Baldasseroni A, Schaafsma F, Cooke RM, Mancini G, Fierro M, Santangelo C, Farioli A, Fucksia S, Curti S, Violante FS, Verbeek J (2010) Search strings for the study of putative occupational determinants of disease. Occup Environ Med 67(7):436-443. https://doi.org/10.1136/oem.2008.044727

Modenese A, Gobba F (2017) Occupational exposure to solar radiation at different latitudes and pterygium: a systematic review of the last 10 years of scientific literature. Int J Environ Res Public Health 15(1):E37. https://doi.org/10.3390/ijerph15010037

Modenese A, Gobba F (2018) Cataract frequency and subtypes involved in workers assessed for their solar radiation exposure: a systematic review. Acta Ophthalmol (epub ahead of print). https ://doi.org/10.1111/aos.13734 
Modenese A, Bisegna F, Borra M, Grandi C, Gugliermetti F, Militello A, Gobba F (2016a) Outdoor work and solar radiation exposure: evaluation method for epidemiological studies. Med Pr 67(5):577587. https://doi.org/10.13075/mp.5893.00461

Modenese A, Farnetani F, Andreoli A, Pellacani G, Gobba F (2016b) Questionnaire-based evaluation of occupational and non-occupational solar radiation exposure in a sample of Italian patients treated for actinic keratosis and other non-melanoma skin cancers. J Eur Acad Dermatol Venereol 30(Suppl.3):21-26. https://doi. org/10.1111/jdv.13606

Njirić S, Misljenović T, Mikulicić M, Pavicević L (2007) Incidence of age related macular degeneration in correlation with age, sex and occupation. Coll Antropol 31(Suppl.1):107-110

Nowak JZ (2006) Age-related macular degeneration (AMD): pathogenesis and therapy. Pharmacol Rep 58(3):353-363

Park SJ, Lee JH, Woo SJ, Ahn J, Shin JP, Song SJ, Kang SW, Park KH (2014) Epidemiologic Survey Committee of the Korean Ophthalmologic Society. Age-related macular degeneration: prevalence and risk factors from Korean National Health and Nutrition Examination Survey, 2008 through 2011. Ophthalmology 121(9):1756-1765. https://doi.org/10.1016/j.ophtha.2014.03.022

Plestina-Borjan I, Klinger-Lasić M (2007) Long-term exposure to solar ultraviolet radiation as a risk factor for age-related macular degeneration. Coll Antropol 31(Suppl.1):33-38

Poole CJM, Basu S (2017) Systematic review: occupational illness in the waste and recycling sector. Occup Med (Lond) 67(8):626-636. https://doi.org/10.1093/occmed/kqx153

Poscia A, Moscato U, La Milia DI, Milovanovic S, Stojanovic J, Borghini A, Collamati A, Ricciardi W, Magnavita N (2016) Workplace health promotion for older workers: a systematic literature review. BMC Health Serv Res 16(Suppl.5):329. https:// doi.org/10.1186/s12913-016-1518-z

Price RB, Labrie D, Bruzell EM, Sliney DH, Strassler HE (2016) The dental curing light: a potential health risk. J Occup Environ Hyg 13(8):639-646. https://doi.org/10.1080/15459624.2016.1165822

Saadat I, Vakili-Ghartavol R, Farvardin-Jahromi M, Saadat M (2012) Association between exudative age-related macular degeneration and the G6721T polymorphism of XRCC7 in outdoor subjects. Korean J Ophthalmol 26(6):423-427. https://doi.org/10.3341/ kjo.2012.26.6.423

Schick T, Ersoy L, Lechanteur YT, Saksens NT, Hoyng CB, den Hollander AI, Kirchhof B, Fauser S (2016) History of sunlight exposure is a risk factor for age-related macular degeneration. Retina 36(4):787-790. https://doi.org/10.1097/IAE.0000000000000756

Shah AR, Del Priore LV (2007) Progressive visual loss in subfoveal exudation in age-related macular degeneration: a meta-analysis using Lineweaver-Burke plots. Am J Ophthalmol 143(1):83-89. https://doi.org/10.1016/j.ajo.2006.09.043

Shaw PX, Stiles T, Douglas C, Ho D, Fan W, Du H, Xiao X (2016) Oxidative stress, innate immunity, and age-related macular degeneration. AIMS Mol Sci 3(2):196-221. https://doi.org/10.3934/ molsci.2016.2.196

Sliney DH (2002) How light reaches the eye and its components. Int J Toxicol 21(6):501-509. https://doi.org/10.1080/1091581029 0169927

Sliney D, Aron-Rosa D, DeLori F, Fankhauser F, Landry R, Mainster M, Marshall J, Rassow B, Stuck B, Trokel S, West TM, Wolffe M (2005) International Commission on Non-Ionizing Radiation Protection. Adjustment of guidelines for exposure of the eye to optical radiation from ocular instruments: statement from a task group of the International Commission on Non-Ionizing Radiation Protection (ICNIRP). Appl Opt 44(11):2162-2176. https://doi. org/10.1364/AO.44.002162

Sui GY, Liu GC, Liu GY, Gao YY, Deng Y, Wang WY, Tong SH, Wang L (2013) Is sunlight exposure a risk factor for age-related macular degeneration? A systematic review and meta-analysis. $\mathrm{Br}$ J Ophthalmol 97(4):389-394. https://doi.org/10.1136/bjophthalm ol-2012-302281

Taylor HR, Keeffe JE (2001) World blindness: a 21st century perspective. Br J Ophthalmol 85(3):261-266. https://doi.org/10.1136/ bjo.85.3.261

Taylor HR, Muñoz B, West S, Bressler NM, Bressler SB, Rosenthal FS (1990) Visible light and risk of age-related macular degeneration. Trans Am Ophthalmol Soc 88:163-178

Tenkate TD (2017) Ocular ultraviolet radiation exposure of welders. Scand J Work Environ Health 43(3):287-288. https://doi. org/10.5271/sjweh.3630

Thapa R, Paudyal G, Shrestha MK, Gurung R, Ruit S (2011) Agerelated macular degeneration in Nepal. Kathmandu Univ Med J (KUMJ) 9(35):165-169. https://doi.org/10.3126/kumj.v9i3.6298

Thürauf JR (1979) Health effects of exposure to ultraviolet and infrared radiation. Report of a WHO-conference in Sofia. Int Arch Occup Environ Health 43(1):69-70. https://doi.org/10.1007/BF00454282

Tomany SC, Cruickshanks KJ, Klein R, Klein BE, Knudtson MD (2004a) Sunlight and the 10-year incidence of age-related maculopathy: the Beaver Dam Eye Study. Arch Ophthalmol 122(5):750-757. https://doi.org/10.1001/archopht.122.5.750

Tomany SC, Wang JJ, Van Leeuwen R, Klein R, Mitchell P, Vingerling JR, Klein BE, Smith W, De Jong PT (2004b) Risk factors for incident age-related macular degeneration: pooled findings from 3 continents. Ophthalmology 111(7):1280-1287. https://doi. org/10.1016/j.ophtha.2003.11.010

Tuo J, Bojanowski CM, Chan CC (2004) Genetic factors of age-related macular degeneration. Prog Retin Eye Res 23(2):229-249. https ://doi.org/10.1016/j.preteyeres.2004.02.001

Ugarte M, Osborne NN, Brown LA, Bishop PN (2013) Iron, zinc, and copper in retinal physiology and disease. Surv Ophthalmol 58(6):585-609. https://doi.org/10.1016/j.survophthal.2012.12.002

Ulrich C, Salavastru C, Agner T, Bauer A, Brans R, Crepy MN, Ettler K, Gobba F, Goncalo M, Imko-Walczuk B, Lear J, Macan J, Modenese A, Paoli J, Sartorelli P, Stageland K, Weinert P, Wroblewski N, Wulf HC, John SM (2016) The European Status Quo in legal recognition and patient-care services of occupational skin cancer. J Eur Acad Dermatol Venereol 30(Suppl.3):46-51. https://doi.org/10.1111/jdv.13609

Virgili G, Michelessi M, Parodi MB, Bacherini D, Evans JR (2015) Laser treatment of drusen to prevent progression to advanced age-related macular degeneration. Cochrane Database Syst Rev 10:CD006537. https://doi.org/10.1002/14651858.CD006537.pub3

Vojniković B, Njirić S, Coklo M, Spanjol J (2007) Ultraviolet sun radiation and incidence of age-related macular degeneration on Croatian Island Rab. Coll Antropol 31(Suppl.1):43-44

Wang AL, Lukas TJ, Yuan M, Du N, Tso MO, Neufeld AH (2009) Autophagy and exosomes in the aged retinal pigment epithelium: possible relevance to drusen formation and age-related macular degeneration. PLoS One 4(1):e4160. https://doi.org/10.1371/journ al.pone. 0004160

Yoshimura N (2010) Age-related macular degeneration and genetics. Clin Exp Ophthalmol 38(1):1. https://doi.org/10.111 1/j.1442-9071.2009.02225.x 